\title{
Segmentation of the Main Himalayan Thrust inferred from geodetic observations of interseismic coupling
}

\author{
Luca Dal Zilio ${ }^{1,2 *}$, Romain Jolivet ${ }^{3}$, \& Ylona van Dinther ${ }^{1,4}$ \\ ${ }^{1}$ Department of Earth Sciences, ETH-Zürich, Sonneggstrasse 5, 8092 Zürich, Switzerland \\ ${ }^{2}$ Division of Engineering and Applied Science, California Institute of Technology, Pasadena, California 91125, USA \\ ${ }^{3}$ Laboratoire de Géologie, Département de Géosciences, Ecole Normale Supérieure, 75231 Paris, France. \\ ${ }^{4}$ Department of Earth Sciences, Utrecht University, The Netherlands \\ *Corresponding author e-mail: dalzilio@caltech.edu
}

\begin{abstract}
Mapping the distribution of locked segments along subduction megathrusts is essential for improving quantitative assessments of seismic hazard. Previous geodetic studies suggest the Main Himalayan Thrust (MHT) is homogeneously locked (or coupled) along its complete length over a down-dip extent of $\sim \mathbf{1 0 0} \mathbf{~ k m}$. However, an increasing number of seismological and geophysical observations suggests the MHT is structurally segmented along strike. Furthermore, coupling appears to vary significantly in subduction zones worldwide, hence the MHT appears as a striking anomaly. Here, we use a recent compilation of geodetic data and a fully Bayesian approach to show that coupling is highly heterogeneous along the MHT, thus reconciling all observations available. Our probabilistic estimate of interseismic coupling along the entire MHT highlights four large, highly-coupled patches separated by three potential barriers of low coupling. Locked patches overlap with estimated rupture areas of historical large earthquake over the past centuries. The coincident spatial variability in coupling, seismicity, prominent active topography, and complexity in earthquake history, suggests a structural segmentation of the Himalayan imposed by inherited tectonic structures from the India-Eurasia collision. This correlation implies that inherited tectonic structures may influence how stress builds up along the MHT and thus may influence the location and size of large Himalayan earthquakes and the growth of the Himalaya.
\end{abstract}

\section{Introduction}

Seismic hazard assessments have important implications for society, providing a basis for building codes, risk assessments, and public policies to mitigate earthquake risk (Shaw et al. , 2018). In this regard, the magnitude $\left(\mathrm{M}_{\mathrm{w}}\right) 7.8$ Gorkha-Nepal earthquake of 2015 was a dramatic reminder of the importance of understanding seismic hazard in the Himalayas (Bilham, 2015) (Fig. 1). This densely populated region has been struck by some of the largest continental earthquakes, including the $\mathrm{M}_{\mathrm{w}} 6.9$ Sikkim 2011, and $\mathrm{M}_{\mathrm{w}} 7.6$ Kashmir 2005 earthquakes. It is also known to have produced 
larger historical earthquakes of magnitude larger than 8, such as the $\mathrm{M}_{\mathrm{w}} 8.5$ Assam 1950 and the $\mathrm{M}_{\mathrm{w}}$ 8.2 1934 Nepal-Bihar earthquakes (Chen \& Molnar, 1990; Sapkota et al. , 2013).

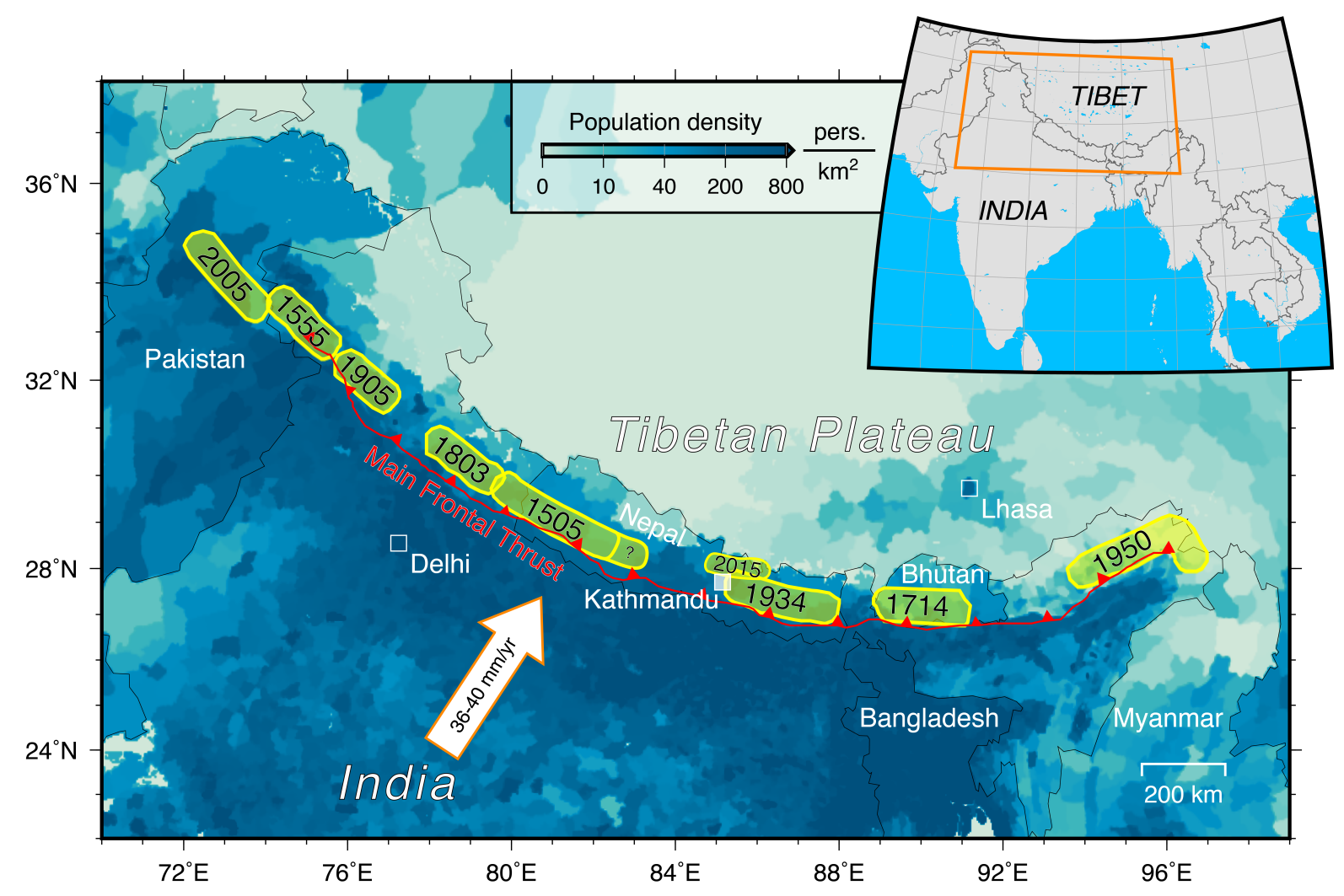

Figure 1: Great earthquakes in the Himalayas since 1500 A.D. Yellow rupture areas of magnitude $>7.5$ and larger events are schematic and represent the published along-arc extent estimates (Bilham \& England, 2001; Bilham, 2009; Kumar et al. , 2010; Bollinger et al. , 2014; Berthet et al. , 2014). Population density data from Ciesin (2005). Inset locates main map. Modified after Hetényi et al. (2016a).

In subduction zones, tectonic shortening imposed by plate motion on locked, seismogenic plate boundary faults leads to elastic stress increase, which is ultimately released by earthquakes (Lay, 2015). Geodetic observations allow to derive spatial variations of strain rates induced by interseismic locking of the main boundary faults. It consists of a mosaic of the plate boundary fault, which is used to map which portions of a plate boundary fault are locked versus those that slip aseismically. In the Himalayas, most large earthquakes have ruptured the Main Himalayan Thrust (MHT), the main plate boundary between the Indian and Eurasian plates. Interseismic strain results from tectonic shortening ( $20 \mathrm{~mm} \mathrm{yr}^{-1}$ across the Himalayas) imposed on a locked interface, the MHT, between those converging plates. The recent development of a large scale, dense network of GNSS stations (Kreemer et al. , 2014) allows to quantify the degree of fault locking and its spatial distribution on the MHT. Fault locking is referred to as coupling, defined as the ratio of the deficit of slip rate in the interseismic period divided by the long-term slip rate imposed by tectonic shortening. This ratio varies from 0 for a portion of the $\mathrm{MHT}$ that slips aseismically at a rate equal to the plate convergence 
rate to 1 for a fully locked fault.

Many models derived from geodetic data suggest interseismic coupling on subduction megathrusts worldwide is spatially heterogeneous, defining locked patches where stress increases more rapidly surrounded by segments that slip aseismically (Chlieh et al. , 2008; Moreno et al. , 2011). Megathrust earthquakes occur to first order on these interseismically locked patches (Loveless \& Meade, 2011). Conversely, previously published models in the Himalayan region indicate that the entire MHT is uniformly locked from the surface to beneath the front of the high range over a width of $100 \pm 20 \mathrm{~km}$ (Ader et al. , 2012; Stevens \& Avouac, 2015). Therefore, the MHT appears to be an anomaly with respect to subduction megathrusts worldwide. In addition, a fully locked MHT does not correlate with the variable size along strike and location of large (M7+) Himalayan earthquakes (Fig. 1). Furthermore, a recent and detailed GPS velocity solution over Bhutan highlights local variations in coupling over a small fraction of the MHT with aseismic slip at shallow depth (Marechal et al. , 2016).

Micro and moderate seismicity throughout the Himalayan arc varies significantly with some well defined active regions, highlighting a potential segmentation of the arc from a seismological point of view (Arora et al. , 2012). This lateral variation in seismic productivity may result from variations in fault geometry, rheology, frictional properties along the fault interface or structural complexities (Mugnier et al. , 2017; Hubbard et al. , 2016; Bilham et al. , 2017; Dal Zilio et al. , 2019). Recent studies also propose that the structure and seismicity may be influenced by the prolongation of subsurface ridges visible in the Indo-Gangetic Plains into the Himalaya (Arora et al. , 2012), a northward prolongation evidenced by the arc-parallel gravity anomalies (Hetényi et al. , 2016b). A segmentation in the seismic productivity or in the structure of the MHT would have important implications for the estimation of the return period and maximum magnitude of major earthquakes. Several studies suggest that a historical event near 1100 AD could have reached magnitude 9 along the Himalayan front (Kumar et al. , 2010; Le Roux-Mallouf et al. , 2016). Such large M9+ events are also required in the Himalayas to balance the moment deficit derived from geodetic strain measurements (Stevens \& Avouac, 2016). If the degree of locking is high all along the MHT, a large M9+ earthquakes could dynamically propagate easily, while a segmented megathrust introduces rupture barriers and thus promotes laterally smaller earthquakes (Hubbard et al. , 2016; Grandin et al. , 2015; Mugnier et al. , 2017).

Considering a potential segmentation of the arc suggested by seismological and morphological features, we should question whether the current coupling models (Ader et al. , 2012; Stevens \& Avouac, 2015) along the MHT are biased by the ill-posed nature of interseismic slip inversions. Because of the non-uniqueness of the solution, (ad hoc) smoothing constraints are often used to regularize slip inversions, effectively smoothing the resulting coupling map over regions with limited data (Loveless \& Meade, 2011). In addition, estimates of coupling usually do not include uncertainties, which complicates any quantitative assessment of the overall strain budget. It therefore appears necessary to quantify the influence of regularization of the inverse problem on the distribution of coupling and to derive uncertainties only driven by data uncertainties and modeling assumptions.

In this study, we use 255 GPS-derived velocities spanning the 1990 s to 2015 and levelling measurements between 1977 and 1990 (Kreemer et al. , 2014; Jackson \& Bilham, 1994). We derive a probabilistic estimate of fault coupling along the MHT using AITar, a Bayesian solver using elements 
of Markov Chain Monte Carlo (MCMC) sampler and tempering (Jolivet et al. , 2015; Minson et al. , 2013; Duputel et al. , 2014). Such probabilistic estimate does not rely on any spatial smoothing. Furthermore, it provides full posterior probability distributions of coupling made of the ensemble of plausible models that fit the observations and are consistent with prior constraints. We consider a uniform prior PDF of coupling along the MHT, meaning we consider all spatial distributions of cou-

pling are a priori equally probable. In addition, we assume $10 \%$ uncertainties on the prediction of the forward model due to variable elastic structure of the Himalayan crust (see Fig. 2-3, and Methods). We then propagate both data and prediction uncertainties and our modeling assumptions into a posteriori model uncertainties to evaluate what is allowed and what is not allowed by the GPS data. We generate 360'000 models corresponding to the posterior distribution of geodetic coupling given measured interseismic velocities.

\section{Methods}

\subsection{Geodetic Observations}

To assess the extent of interseismic coupling, we use an updated set of GPS-derived velocities spanning the 1990 s to 2015 . It was recently used to estimate the width of coupling across the MHT through a series of two-dimensional transects (Lindsey et al. , 2018) (Fig. 2). These velocities are from a number of published studies and combined into a consistent reference frame by reducing the best-fitting pole of rotation between overlapping sites in each data set (Kreemer et al. , 2014). Velocities for stations within China were combined with the reprocessed, updated velocity field (Zheng et al. , 2017). To better resolve the pattern of coupling we also include levelling measurements from the Survey of Nepal collected between 1977 and 1990 (Jackson \& Bilham, 1994). Levelling data provide measurements of interseismic uplift rate. As pointed out by Ader et al. (2012), uncertainties on the levelling data are low with respect to those on the GPS-derived vertical rates and help constrain well the pattern of coupling locally.

Following the approach of Stevens \& Avouac (2015), our fault model considers the total length of the arc of roughly $2000 \mathrm{~km}$, from $73^{\circ} \mathrm{E}$ to $96^{\circ} \mathrm{E}$ (Fig. 2). The dip angle is set to $10^{\circ}$ as in previous studies (Stevens \& Avouac, 2015; Ader et al. , 2012). Due to the arcuate and irregular shape, we divide the fault geometry into four planar sub-faults blocks. These sub-faults are discretized in 353 triangles with variable size, smaller near the surface and larger down-dip. As estimates of the extent of plate coupling depend on the direction and rate of the plate convergence, we set a specific convergence rate and azimuth for each sub-fault based on plate motion models and regional geodetic measurements (see Table 1).

We also assume that the otherwise rigidly moving India plates is fragmenting around the eastern end of the Himalayan arc where there is evidence for internal deformation (Vernant et al. , 2014). To account for this deformation, we consider two distinct blocks and related subnetworks: India and the Shillong block south of the eastern Himalaya (Fig. 2). The elastostatic Green's functions of each sub-fault and block, relating unit slip on each patch to surface displacements at the data locations, are thus computed assuming a different long-term convergence rate and azimuth. The inversion solves for the poles of rotation with respect to India, as well as the coupling pattern. 


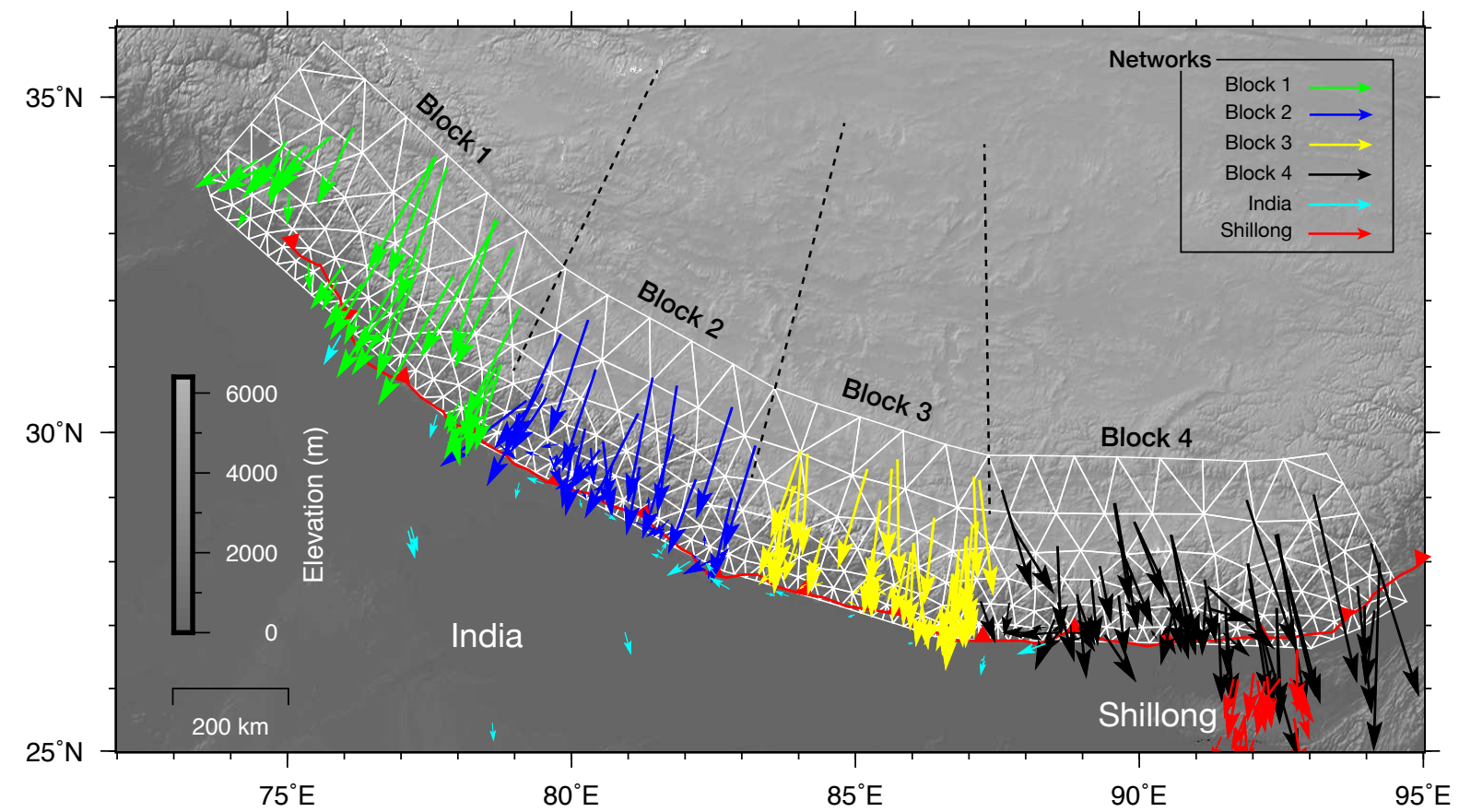

Figure 2: Top view of the fault and GPS network employed in this study. The red line shows the surface trace of the Main Frontal Thrust. White triangular mesh is the fault discretization used in this model. Dashed black lines are the boundaries between different regions of uniform long term slip rate. GPS network is divided in the following subnetworks: block-1 (green), block-2 (blue), block-3 (yellow), block-4 (black), India (light blue), and Shillong (red).

We predict the response to subsurface fault slip at each data (GPS and levelling) location assuming a stratified semi-infinite elastic medium (Simons et al. , 2002; Zhu \& Rivera, 2002). Our elastic space consists of 3 layers with elastic properties following roughly the average properties of the crust in the region (Pandey et al. , 1995) (Fig. 3). This 1D model was determined from the study of quarry blasts and from the distribution of apparent velocity of the first arriving phases generated by microseismic events occurring from a few kilometres to regional distance within the extent of the lesser Himalaya. Although the structure of the range is not one-dimensional, this simple model was found to be consistent with ray tracing modelling. It is also consistent with computed crustal thickness and velocity in the Lesser Himalaya determined from deep seismic profiling (Hirn et al. , 1984). Most of the microseismicity activity observed from 1985 to 1993 has occurred within the Lesser Himalaya where the velocity model has been constrained (Pandey et al. , 1995).

\subsection{Bayesian analysis}

We consider the forward problem $\mathbf{d}=\mathbf{G m}$, where $\mathbf{d}$ is the vector containing the horizontal component of the GPS-derived velocities and of the vertical displacement of the levelling-derived measurements, $\mathbf{m}$ is the vector of model parameters, and $\mathbf{G}$ is the matrix of the response to slip on the faults at the data points and the geometric transformations in GPS and levelling data.

We solve the inverse problem to infer the distribution of model parameters $(\mathbf{m})$ consistent with our data $(\mathbf{d})$. The solution to this inverse problem is non-unique and large uncertainties on the 


\begin{tabular}{lll}
\hline Longitude & Slip rate $(\mathbf{m m} / \mathbf{y r})$ & Reference \\
\hline 76.0 & 13.3 & Thakur et al. (2014) \\
\hline 82.0 & 19.0 & Mugnier et al. (2004) \\
\hline 85.8 & 18.2 & Bollinger et al. (2014) \\
\hline 90.3 & 20.8 & Berthet et al. (2014) \\
\hline
\end{tabular}

Table 1: Long term slip rates from geomorphic studies used in this study.
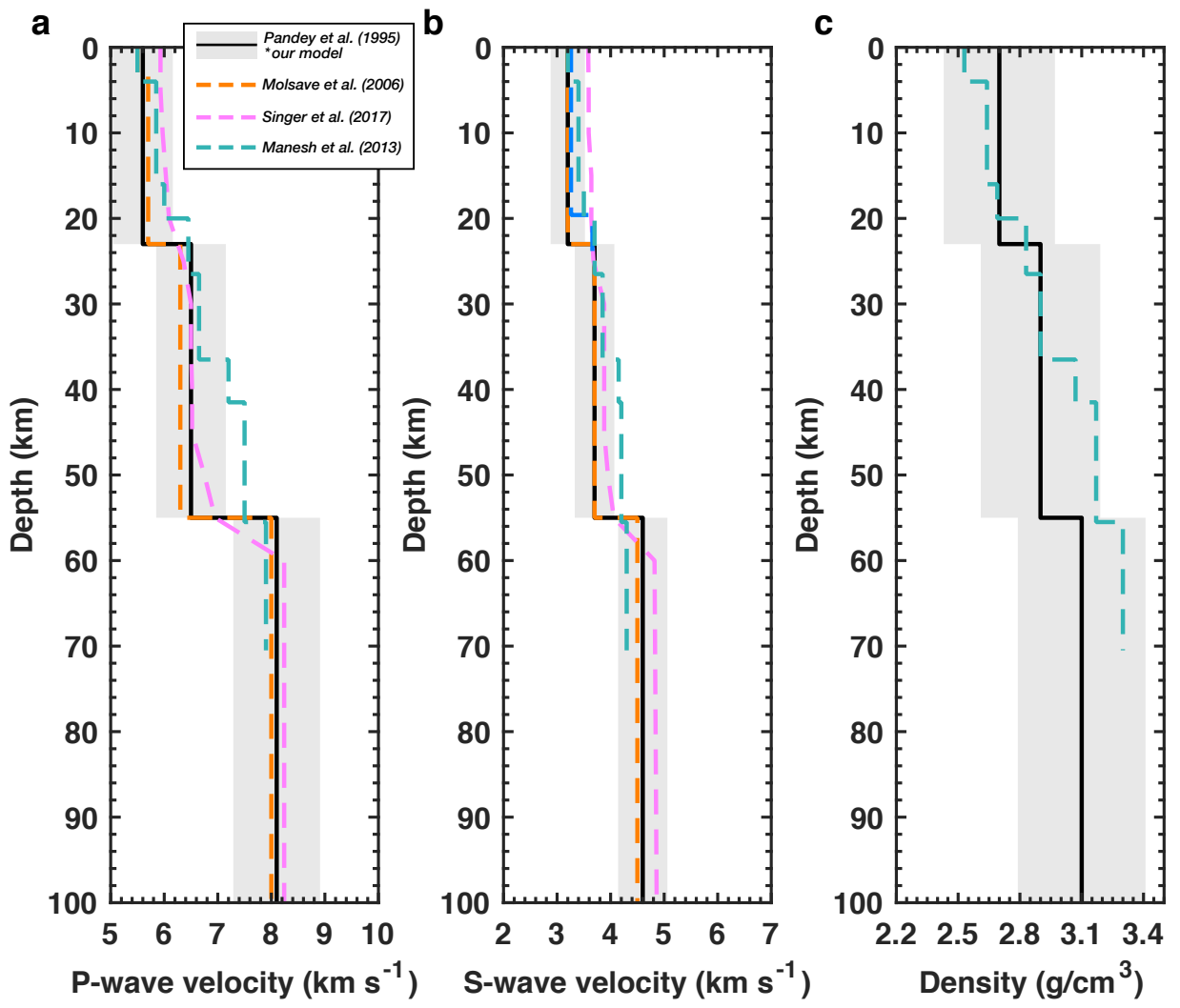

Figure 3: Earth model: (a) P-wave velocity, (b) S-wave velocity and (c) Density used in this study for Green's function (GF) calculations. The layered model used in this study for Green's function (GF) calculations is plotted as a solid black line (Pandey et al. , 1995). Dashed lines refer to the other models used to constrain the uncertainties on model prediction (Mahesh et al. , 2013; Monsalve et al. , 2006; Singer et al. , 2017). Grey areas are the standard deviation of the probability density function, representing our confidence level on the elastic properties, as used to build the model prediction error $\left(\mathbf{C}_{\mathrm{p}}\right)$.

parameters are expected. Therefore, instead of deriving a single model, we explore all the potential solutions using a Bayesian approach to derive the posterior PDF of our model given our set of data, $\mathbf{p}(\mathbf{m} \mid \mathbf{d})$ (Minson et al. , 2013). We thus derive a probabilistic estimate of the degree of fault locking along the MHT. Following Bayes's theorem, we write the posterior PDF as:

$$
\mathbf{p}(\mathbf{m} \mid \mathbf{d})=p(\mathbf{m}) \exp \left[-\frac{1}{2}(\mathbf{d}-\mathbf{G m})^{T} \mathbf{C}_{\chi}^{-1}(\mathbf{d}-\mathbf{G m})\right]
$$


where $\mathbf{p}(\mathbf{m})$ is the prior PDF of the model that describes our state of knowledge before acquiring data, $\mathbf{d}$ is the data vector, $\mathbf{G}$ the Green's functions matrix, and $\mathbf{m}$ is the vector of model parameters.

$\mathbf{C}_{\chi}$ is the covariance matrix in the data space, defined as the sum of the data covariance matrix $\mathbf{C}_{\mathbf{d}}$, (i.e., measurement error matrix) and the prediction error matrix, $\mathbf{C}_{\mathbf{p}}$, which describes uncertainties in our elastic model for the crust:

$$
\mathbf{C}_{\chi}=\mathbf{C}_{\mathbf{d}}+\mathbf{C}_{\mathbf{p}}
$$

We account for prediction uncertainties due to inaccuracies in this layered elastic model using the approach of Duputel et al. (2014). The uncertainty on the elastic structure, presented as grey standard deviation in Fig. 3, is estimated by comparing previously published models across the all Himalayan region. We need a careful description of errors in order to not overfit the data and produce reasonable estimates of coupling uncertainties on each portion of the megathrust. Considering the variability and uncertainties on the $1 \mathrm{D}$ velocity models (Fig. 3) we include 10\% uncertainty on the elastic properties of each layer of the elastic half-space. Previous studies have shown that not including the prediction errors when sampling for posterior PDF of coupling may lead to biased results (Jolivet et al. , 2015).

The solution of the inverse problem is the posterior ensemble of all plausible interseismic coupling models $(\mathbf{m})$ that fit the GPS data (d) and that are consistent with our prior hypotheses. We test two different prior hypothesis: (1) a uniform PDF assuming no prior knowledge on the model parameters and (2) a heavily-constrained (that is, binary) prior. To sample the posterior PDF we use AlTar, a parallel Markov Chain Monte Carlo (MCMC) algorithm based on the Cascading Adaptive Transitional Metropolis in Parallel (CATMIP) formalism (Minson et al. , 2013). Using multiple MCMC chains in parallel, AITar initially samples the prior PDF, $\mathbf{p}(\mathbf{m})$, and then slowly increases the information brought by the data until it samples the posterior PDF. The implementation is accelerated by Graphic Processing Units (GPUs), allowing us to run thousands of chains in parallel. We generate 360 '000 models corresponding to the posterior information on geodetic coupling given measured interseismic velocities. We perform a series of Bayesian inversions and we find that this number of models is enough to reach a convergence towards a constant posterior probability density function. Our final solution consists of an ensemble of models that are statistically distributed according to the posterior PDF.

\section{Interseismic coupling distribution}

The posterior mean coupling model shows remarkable spatial variations in interseismic coupling, both down-dip and along-strike the MHT (Fig. 4a). We infer discrete highly-coupled segments along the fault extending throughout the arc. Coupling is high at the front, where the MFT reaches the surface and the resolution resulting from observations is highest. Down-dip, coupling tapers to negligible values around 100-120 km from the Main Frontal Thrust. From west to east, we observe a large lateral variability in geodetic coupling. Four large (ca. $300-450 \mathrm{~km}$ ) and discrete highlycoupled segments $(>0.8)$ are separated by three relatively smaller $(c a .100 \mathrm{~km})$ regions with lower coupling $(<0.3)$. These lateral variations of coupling raise two fundamental questions. First, are these variations a robust feature driven by the data? Second, what difference between our approach 
and previously published methods leads to the emergence of these low coupling segments along the MHT?

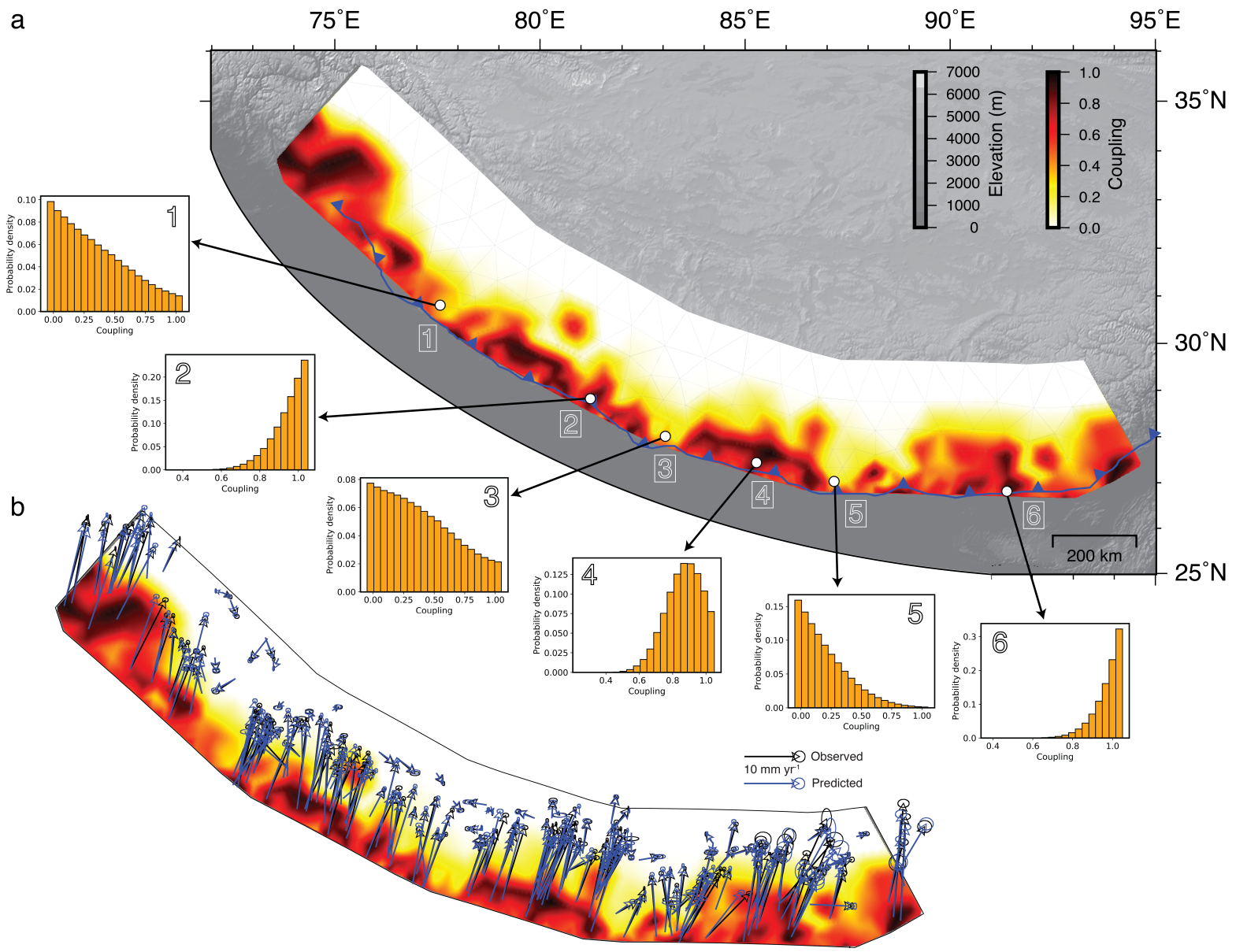

Figure 4: Posterior mean coupling model of the Himalayan megathrust. a, The resulting posterior mean model accounts for data uncertainties and $10 \%$ of prediction uncertainties (see Methods for details). Coupling values are inverted at each triangle knot. For each of the histograms, orange bars are the marginal probability densities at discrete nodes of the fault model. Thin grey lines represent the fault mesh. Solid blue line shows the surface trace of the Main Frontal Thrust. b, Same posterior mean model with the GPS displacement and model predictions plotted as black and blue arrows, respectively.

We interrogate the posterior PDF of coupling to assess the robustness of our estimate by considering the local marginals of coupling (nodes 1-6 in Fig. 4a). Marginal PDFs for nodes 2, 4, and 6 show a $>75 \%$ probability that fault coupling exceeds 0.8 . On the other hand, for node 1 and 5 , we infer a $68 \%$ probability that fault coupling is lower than 0.4 , confirming a high probability of low coupling. In contrast, the shape of the cumulative distribution function of coupling on node 3 suggests a wider range of probable values, not far from the initial prior distributions (i.e., uniform probability of coupling) but still tending towards lower values of coupling. This similarity of prior and posterior distributions suggests the data are less informative to derive fault coupling along this limited section of the model. Although our inversions include larger covariances compared to previous studies 
(Ader et al. , 2012; Stevens \& Avouac, 2015), observed vs. predicted horizontal GPS displacements (Fig. 4b) and residuals (Fig. 5) from our mean model show a good agreement with the geodetic measurements.

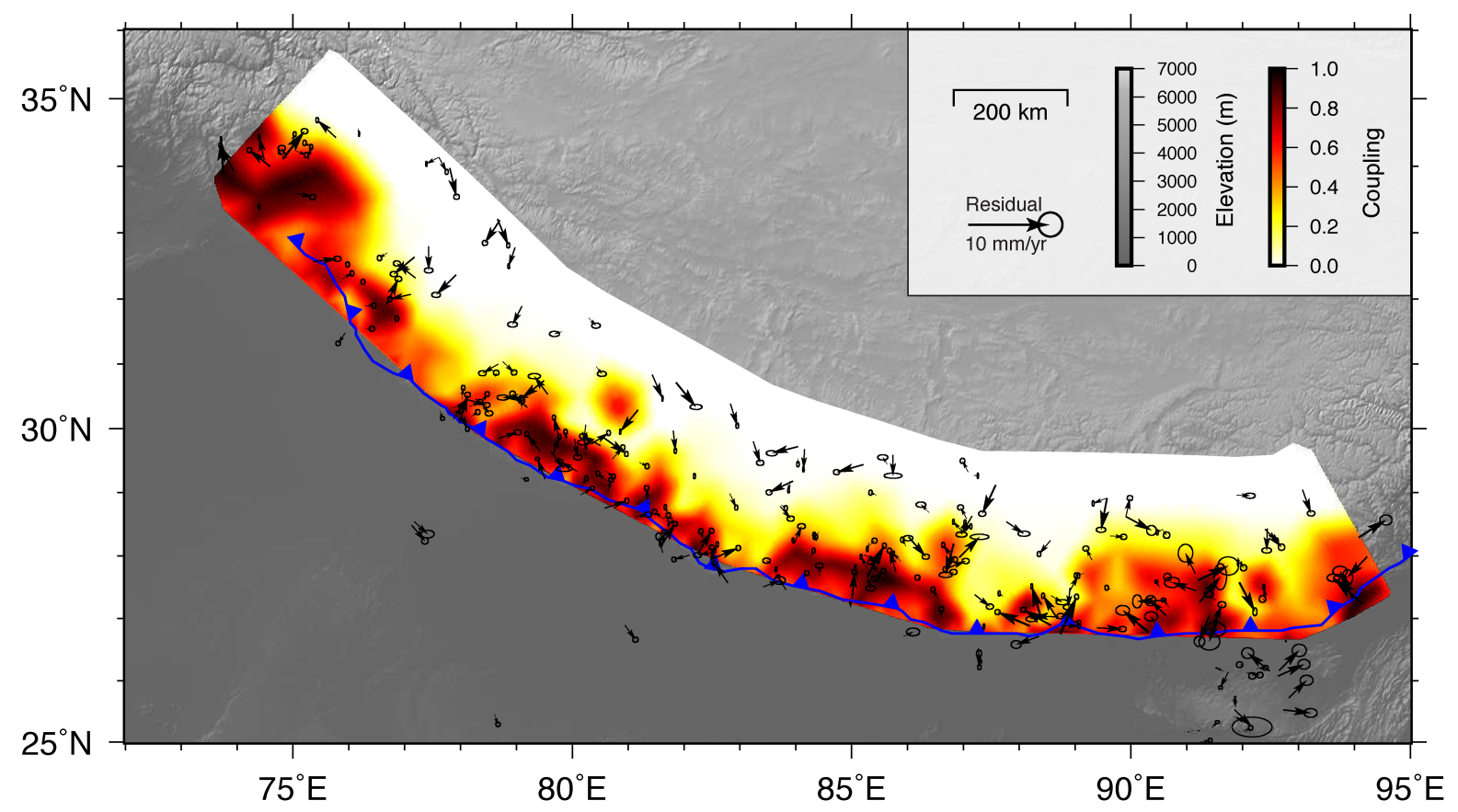

Figure 5: Posterior mean coupling model of the Himalayan megathrust shown in Fig. 4 and residuals to the GPS data, with uncertainty ellipses. Ellipses show the uncertainties at the $67 \%$ confidence level.

However, it is important to note that the regions with lower coupling are where the MHT has a slightly different azimuth and convergence rate, and where the GPS data are less dense (see Methods for details). To check the reliability of our results we perform another test in which we assume a uniform fault with a constant convergence rate along-strike. Despite small variations, these results are very similar and the regions with low coupling are still easily detectable (see Fig. 6). These results thus provide strong evidence that the observed megathrust segmentation is consistent with the data and the given the posterior uncertainties.

For comparison, instead of assuming a uniform non-informative prior, we consider a highlyconstrained prior PDF distribution. In particular, we assume that the MHT is highly-coupled from the surface to 18-km-depth and with negligible coupling at depths greater than $20 \mathrm{~km}$. To do so, we consider a tight Gaussian prior PDF with a standard deviation of $10 \%$, centered on 1 from the surface to 18-km-depth (i.e., fully locked) and on 0 for depths greater than $20 \mathrm{~km}$ (i.e., fully creeping). All other assumptions and hypothesis are kept identical to our preferred model. This strong assumption is based on previous geodetic studies using GPS campaign and leveling measurements (Bollinger et al. , 2004), a few continuous GPS stations (Bettinelli et al. , 2006), and a recent physics-based forward model of the Himalayan seismic cycle (Dal Zilio et al. , 2019). Also, the location of the down-dip end of the locked fault zone is consistent with the seismicity pattern observed in Nepal Himalaya (Cattin \& Avouac, 2000), and the postseismic deformation following the $2015 \mathrm{M}_{\mathrm{w}} 7.8$ 


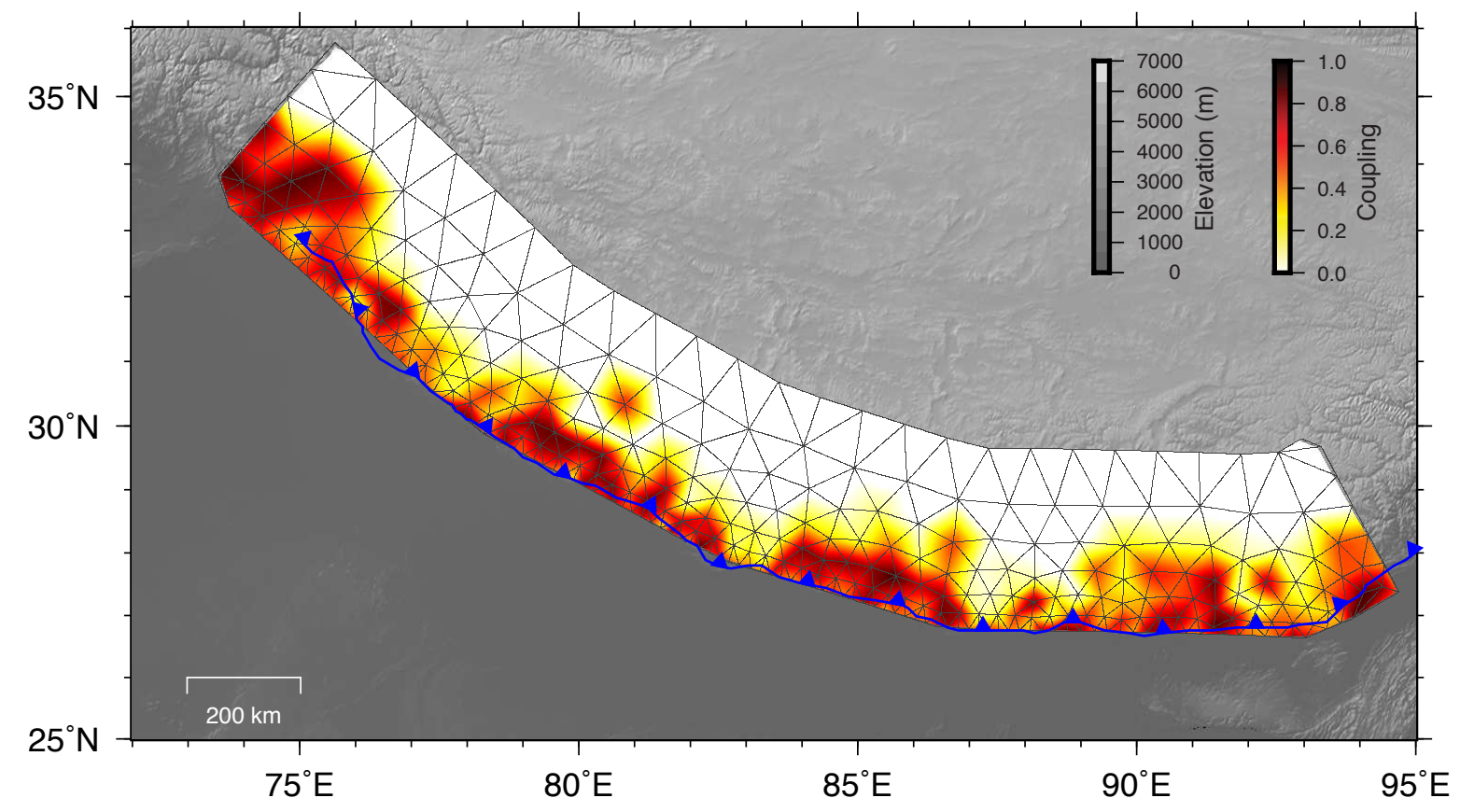

Figure 6: Posterior mean coupling model assuming a homogeneous convergence rate. The resulting posterior mean coupling model is obtained assuming a constant convergence rate along-strike, with no along-strike blocks (see Fig. 2). Thin black lines represent the fault parametrization. Solid blue line shows the surface trace of the Main Frontal Thrust.

Gorkha earthquake (Gualandi et al. , 2017). By assuming that the MHT is locked from the surface to a certain depth, these previous studies found a satisfying fit to the data with a fault dipping about $10^{\circ}$ to the north and a down-dip end of the locked part of the fault about $100 \mathrm{~km}$ along dip from its surface trace.

The posterior mean model suggests the MHT is highly-coupled from its surface expression along the Himalayan foothills to beneath the front of the high range about $100 \mathrm{~km}$ to the north (see Fig. 7). In general, coupling is nearly binary (1-to-0), with a sharp transition between the coupled and creeping zones, similarly to what has been observed in previous studies (Ader et al. , 2012; Stevens \& Avouac, 2015). This distribution of coupling is actually very close to the prior PDF we have considered. Strikingly, residuals are of the same order of magnitude as in our preferred model with uniform prior. This leads to the conclusion that both models, the one assuming a heavily constrained prior and the one with a uniform prior, fit the data almost equally well and are both possible. However, examination of marginal posterior PDFs suggest that the model derived from highly-constrained prior is only a subset of potential models. As shown by marginal PDFs of coupling on node 1, 3 , and 5 (Fig. 7), models with high coupling are not excluded, but they are less probable than low coupled models given the available data. Homogeneous coupling along the MHT thus results mainly from a strong prior assumption, which may derive from smoothing of the solution. On the other hand, relaxing this hypothesis reveals a complex distribution of coupling and this complex distribution is more probable given the available data as shown by the posterior uncertainties directly translated from the data. 

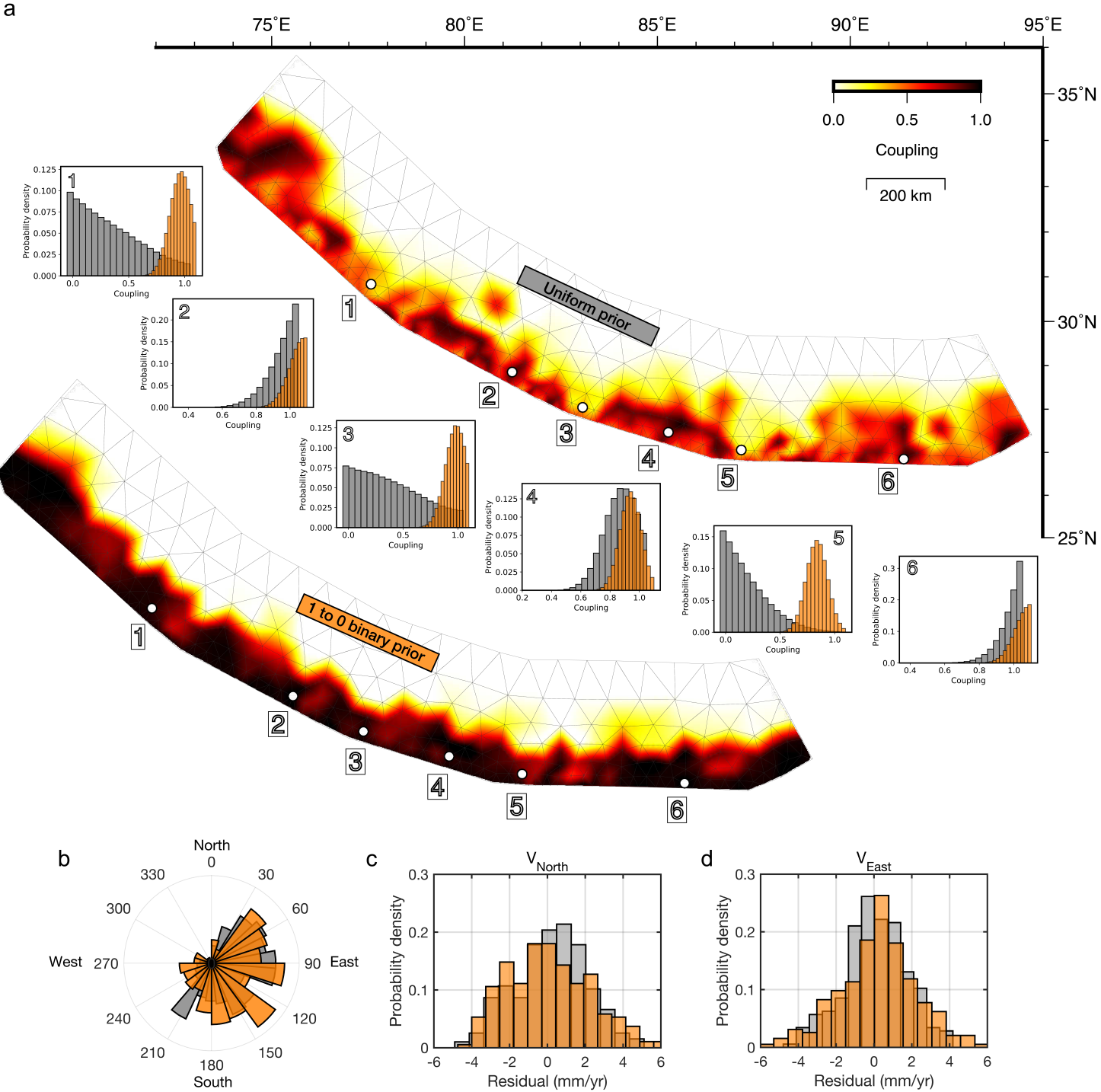

Figure 7: Comparison of coupling models, probability density functions and residuals of the GPS data. a, Top: posterior mean solution shown in Fig. 4 assuming a uniform prior. Bottom: posterior mean solution of model incorporating a strongly constrained 0-to-1 binary prior. Histograms indicate the marginal probability densities at discrete 6 nodes of the fault of models with uniform prior (grey) and binary prior (orange). b, Rosetta histograms showing the orientation of the residuals of the two models. c-d, Probability density distributions of residuals on both north and east velocity components.

\section{Segmentation of the Himalayan megathrust and seismicity}

The spatial variability of interseismic coupling is an important factor to consider in interpreting relationships with the slip distribution of historical ruptures (Fig. 8). Along-strike, low coupling regions around nodes 1, 3, and 5 (Fig. 4a) coincide with three subsurface Indian basement ridges in the Indo-Gangetic plains: The Delhi-Haridwar ridge (DHR), the Faizabad ridge (FR), and the MungerSaharsa ridge (MSR). These subsurface basement ridges extend northward across the Himalayan 


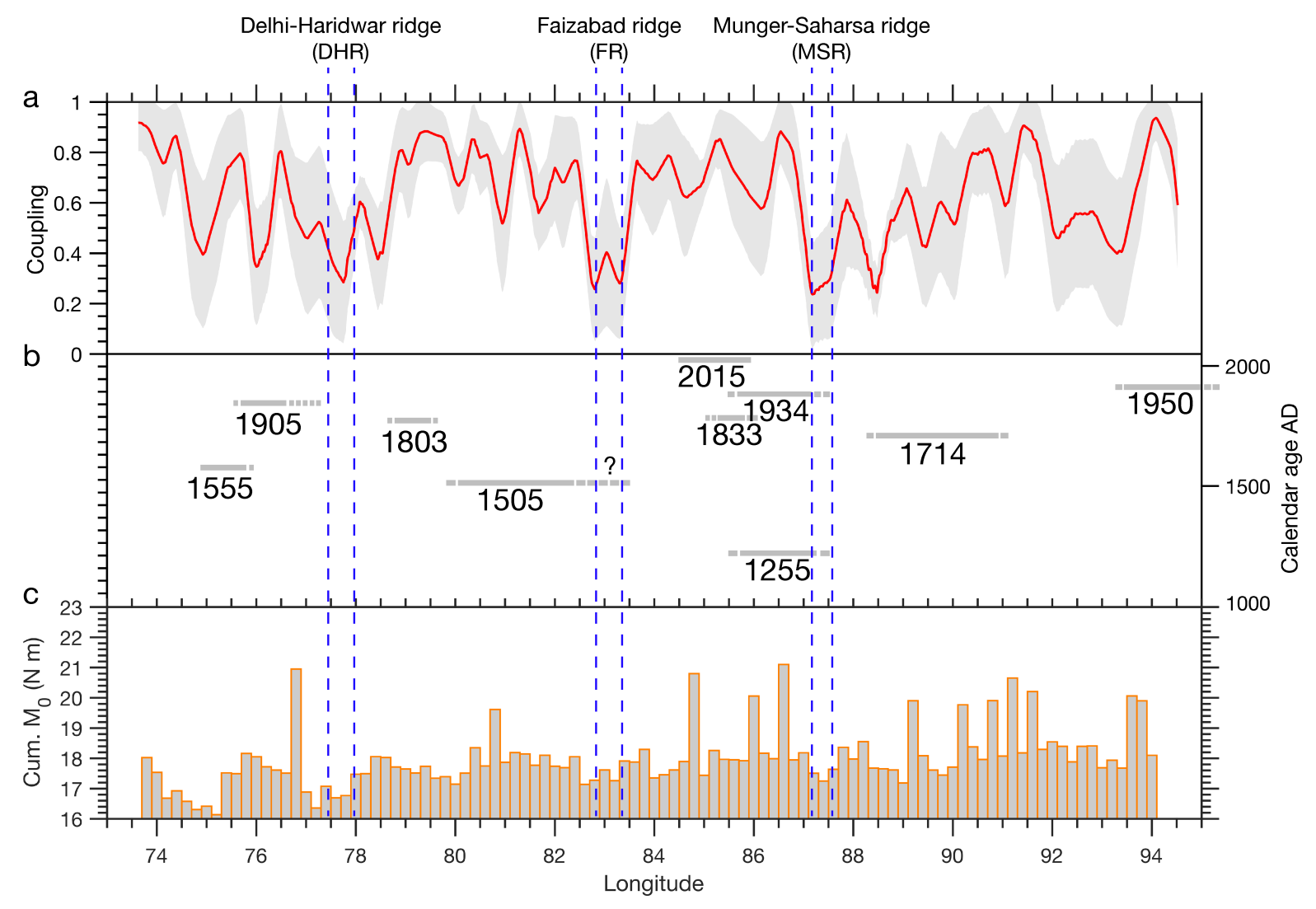

Figure 8: Comparison between along-strike variability of coupling, lateral extension of historical $\mathbf{M}>7.5$ earthquakes, location of the subsurface ridges, and cumulative seismic moment released. a, arc-parallel coupling profile at $45-50 \mathrm{~km}$ from the Main-Frontal-Thrust, derived from the posterior mean coupling model shown in Fig. 4. Shaded grey area represents the corresponding 2- $\sigma$ deviation. Blue dashed lines indicate the location of the subsurface ridges in the Indo-Gangetic plains at the Main Frontal Thrust: DHR - Delhi Hardwar ridge; FR - Faizabad ridge; MSR - MungerSaharsa ridge. b, Known major and great earthquakes in the Himalaya. The lateral extension of the 1555, 1505, and 1255 earthquakes is speculative. The medieval event in Bhutan is after Hetényi et al. (2016a). The 1905 Kangra earthquake rupture is after Wallace et al. (2005). Other instrumentally recorded events on this diagram are the $1905 \mathrm{M} 7.9 \mathrm{Kangra}$ earthquake, the 1934 M8.0 Bihar earthquakes, and the 2015 M7.8 and M7.3 events in the Kathmandu region. c, Lateral variation of cumulative seismic moment released of $M>4.5$ earthquakes across the Himalayan belt (USGS catalog). The seismicity is defined within $250 \mathrm{~km}$ north of the Main Frontal Thrust.

foothills and they might have affected the development of the arcuate shape and the morphology of the Himalayan arc. They have been detected first from basin thickness changes (Gahalaut \& Kundu, 2012), and they are confirmed by the analysis of anomalous transient geomagnetic variations and arc-parallel gravity anomalies (Hetényi et al. , 2016b; Arora et al. , 2012). They typically include oblique to transverse synclines, folds, fracture zones or faults athwart the strike of the Himalaya, and they are associated with normal faulting and strike-slip seismicity (Valdiya, 1976). Details of the origin and nature of the lineaments, however, remain mostly obscure at present although it is believed that more extensive structures are in tectonic continuation from the Indian shield (Valdiya, 1976).

The subduction of these major tectonic structures is likely related to a segmentation in the seis- 
mic behavior of the MHT. Despite uncertainties, the rupture extent of major and great Himalayan earthquakes for past two hundred years appears to correlate with the regions of ridge subduction and the pattern of coupling (Fig. 8b). For example, the eastern edge of the 1905 Kangra earthquake rupture appears to approximately coincide with the Delhi-Hardwar ridge (Gahalaut \& Kundu, 2012; Wallace et al. , 2005). The western edge of the 1803 rupture, though not well constrained, abuts the Delhi-Hardwar ridge (Rajendran \& Rajendran, 2005). The 1934 Nepal Bihar earthquake rupture propagated eastward until or into the Munger-Saharsa ridge (Hough \& Roger, 2008). However, it should be noted that an error of about $50 \mathrm{~km}$ could exist in the estimation of the rupture extent and rupture dimensions, and in the northward extrapolation of the ridges under the Himalayan region (Gahalaut \& Kundu, 2012).

Recorded $\mathrm{M} \geq 4.5$ earthquakes (USGS catalogue) suggest a segmentation of the Himalayan arc (Fig. 8c). Cumulative seismic moment released shows along-strike variations with less seismic moment released in the three regions corresponding to the subsurface ridges. In particular, the cumulated effect of all smaller events does not reach that of a single M6 event. Furthermore, low seismicity across the Faizabad ridge has been evidenced by a dense seismic network in Nepal (Ader et al. , 2012). Relocated microseismic activity (Mahesh et al. , 2013; Ader et al. , 2012), which extends over two regions from $77^{\circ} \mathrm{E}$ and $81^{\circ} \mathrm{E}$ and from $81^{\circ} \mathrm{E}$ to $87^{\circ} \mathrm{E}$, respectively, follow the downdip edge of the highly-coupled patches quite well (Fig. 9). East of Bhutan, in Arunachal Pradesh, there is a seismically active band that extends into the orogen. Also, the cluster of seismicity extending into the Himalayan orogen at $77.5-78^{\circ} \mathrm{E}$ turns northward as a possible continuation of the Delhi-Haridwar ridge.

Most of this background seismicity does not occur on the MHT itself, but rather within a 5-10 km size volume around the down-dip end of the locked fault zone (Avouac, 2015a). Assuming that the instrumental record is representative of the long-term seismicity, such spatial variability in seismic moment released suggests that stressing rates are lower where the ridges are subducting, which coincides with low coupling along the MHT. Where the MHT is locked, stress builds up faster and thus results in higher microseismic activity. Conversely, regions with low coupling may be associated with lower stress build up and lower microseismic activity (Bollinger et al. , 2004).

\section{Coupling vs. topography}

Assuming that coupling is stable over geological times, the resulting pattern of strain should influence the construction of topography locally. To first order, topography contour lines show how the Himalaya rise abruptly at a distance of about $120-150 \mathrm{~km}$ from the Main Frontal Thrust (Fig. 10a). Notably, the down-dip end of the highly-coupled section of the MHT is spatially coincident with the abrupt rise in topography. This confirms that the down-dip limit of the brittle-ductile transition is located where the shear stress accumulation is the highest, and drops under topography greater than $3500 \mathrm{~m}$ of elevation (Bollinger et al. , 2004). To second order, we identify frontal topography cusps where the subsurface ridges subduct under the arc, especially in the case of the FR and MSR, as highlighted by the position of the $2000 \mathrm{~m}$ contour line with respect to the Main Frontal Thrust. These cusps could have formed during earlier episodes of subduction when the ridges were subducting at that location about 10 million years ago (Gahalaut \& Kundu, 2012). In addition, 


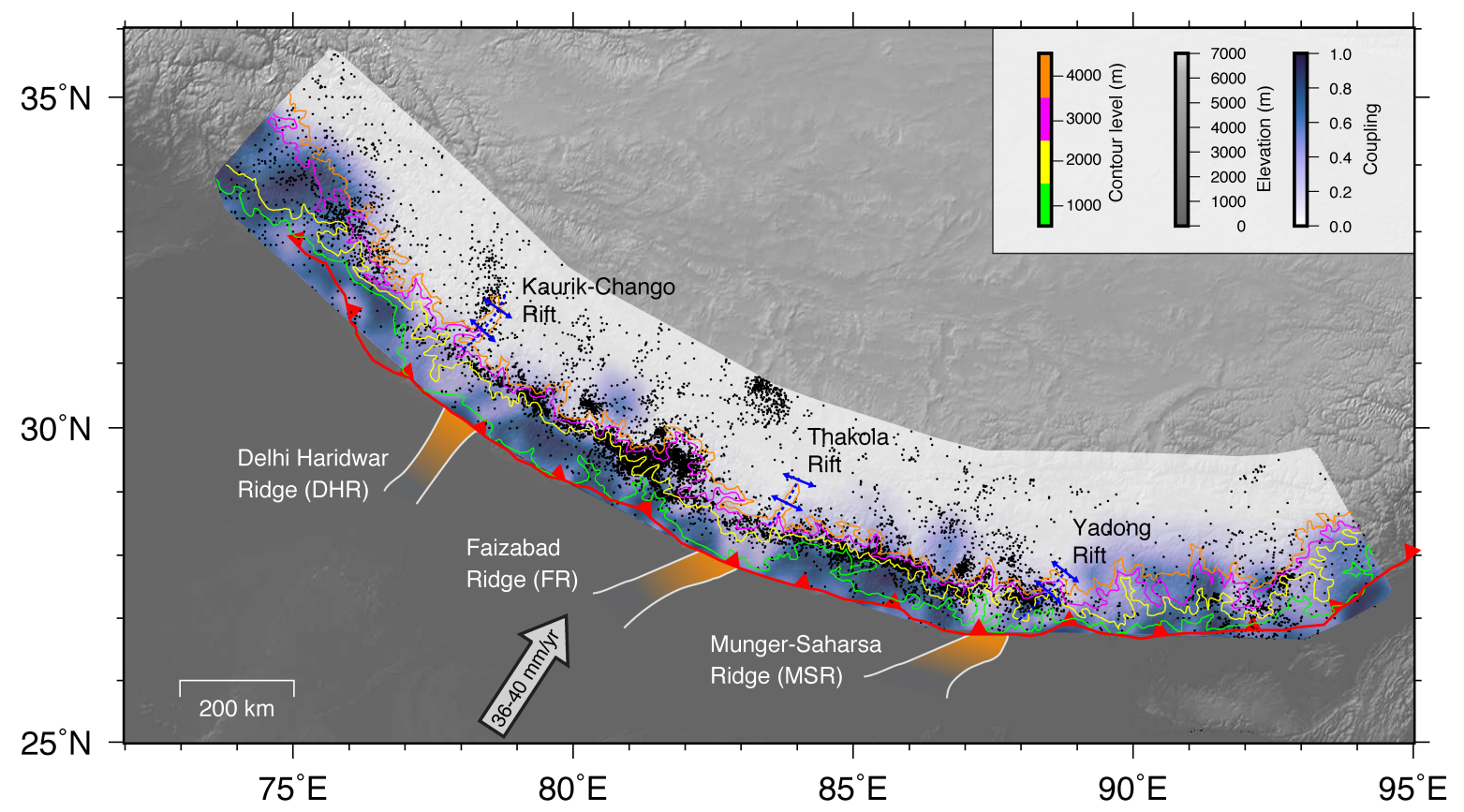

Figure 9: Comparison between topography, interseismic coupling, and (micro-)seismicity. Seismicity within Nepal is from an NSC catalog (Ader et al. , 2012). Seismicity between $\sim 77^{\circ} \mathrm{E}$ and $81^{\circ} \mathrm{E}$ is from Mahesh et al. (2013), and the remainder is from National Earthquake Information Center (NEIC). Solid coloured lines show the topography contour lines. Dashed blue lines indicate the location of the Kaurik-Chango, Thakola, and Yadong rifts. Orange patches indicate the location of the subsurface ridges beneath the Indo-Gangetic Plains. The Main Frontal Thrust is outlined in red.

the largest across-strike graben of the Himalayan belt, the Kaurik-Chango Rifts, the Thakola Rifts and the Yadong Rifts, lie in the prolongation of the three ridges (Fig. 10a). In particular, normal faulting earthquakes continuously occur along N-S fault planes in the Kaurik-Chango Rift (Gahalaut \& Arora, 2012), where the eastern limit of the 1905 Kangra earthquake is located. Possibly, the Kaurik-Chango Rift keeps this part of the Himalayan seismic belt in a dilated (or low stress) state so that earthquake ruptures along the MHT do not extend through it. It should be noted, however, that the assumption of a linear extension in the trend of these ridges below the Himalaya is uncertain and that the ridges may in fact deviate from their extrapolated linear trend.

A link between topography and coupling suggests a long-term influence of the seismic behavior of the megathrust and topography building. One possibility to reconcile the segmentation of topography and that of coupling is to consider the topographic effects of ridge subduction. In subduction zones, seafloor observations (Singh et al. , 2011) and numerical experiments (Ruh et al. , 2016) suggest that subduction of large topographic structures (e.g., seamounts) result in a bulge above the underthrusting seamount and normal faults within the overriding plate. If this holds for the Himalayan orogen, the long-term passage of these three basement ridges could explain the topography cusps and the arc-perpendicular normal faults. This is speculative but possible. More in general, the correlation between the pattern of interseismic coupling and the topography suggests that segmentation and effective frictional properties vary little in time, while irrecoverable strain of the Himalayan 
a

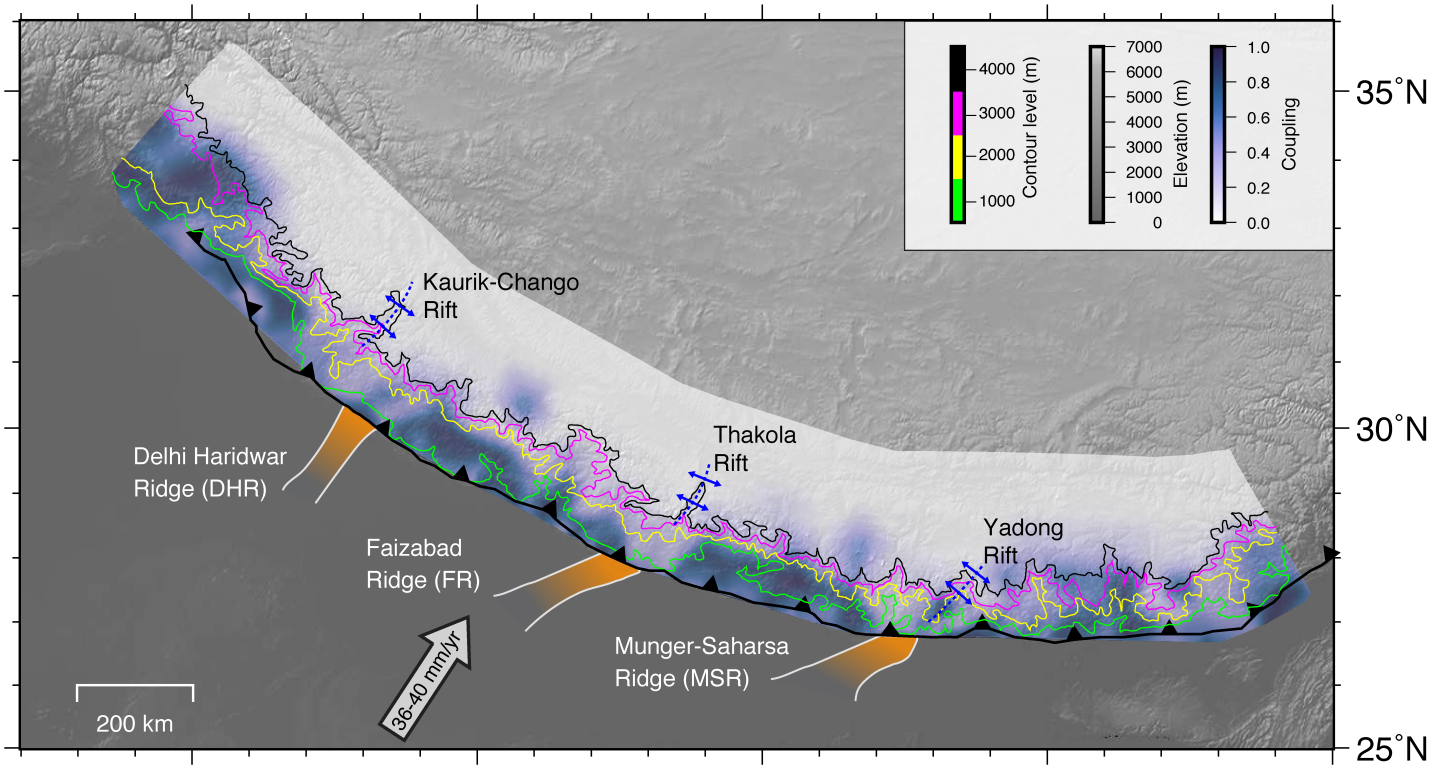

b

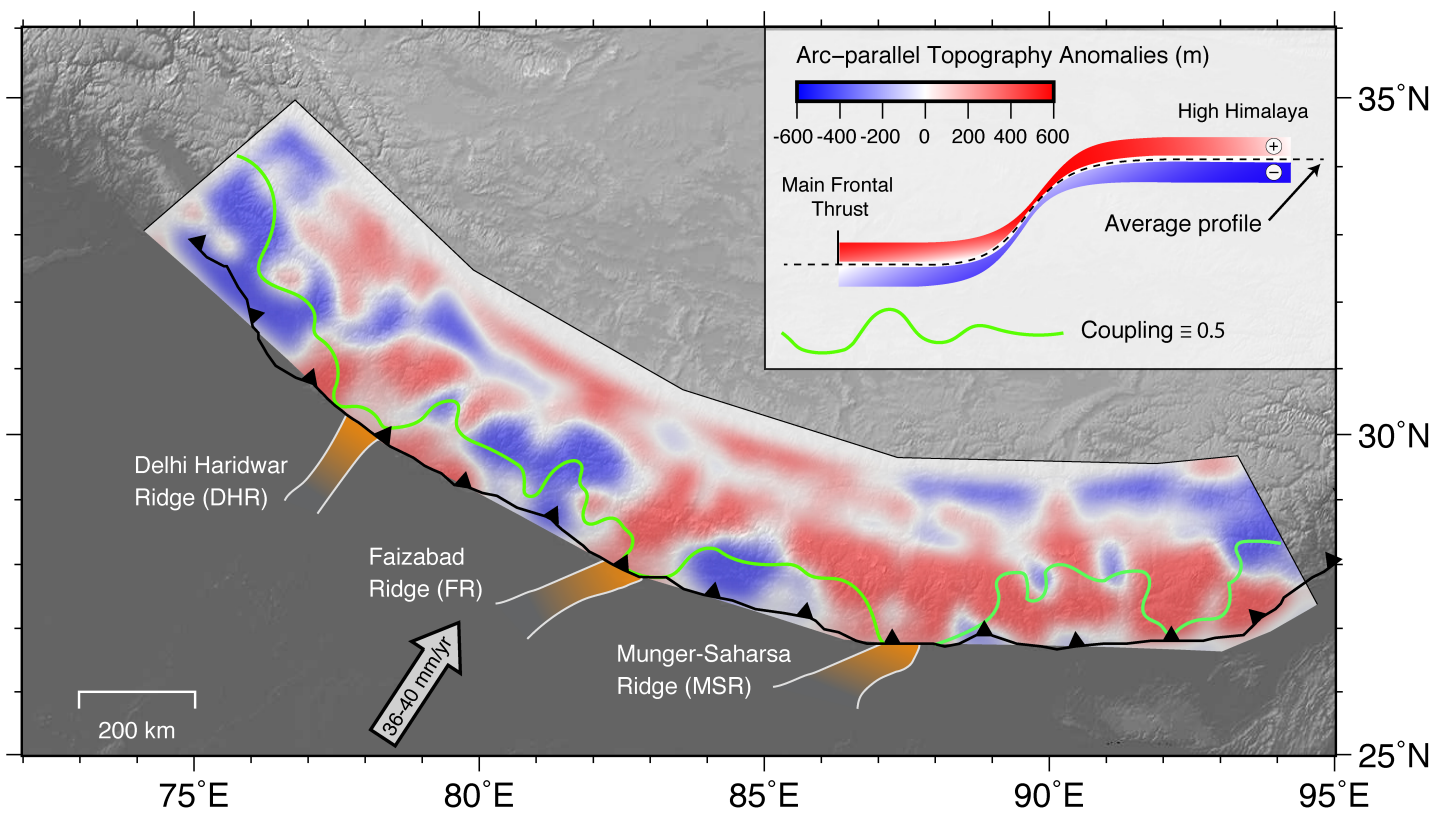

Figure 10: Interseismic coupling vs. topography. a, Comparison between the present-day topography and coupling distribution inferred from the posterior mean coupling model shown in Fig. 4. Blue colormap displays the interseismic coupling pattern. Solid coloured lines show the topography contour lines. Dashed blue lines indicate the location of the Kaurik-Chango, Thakola, and Yadong rifts. b, Arc-Parallel Topography Anomalies after smoothing with a $30-\mathrm{km}$ radius circle (Hetényi et al. , 2016b). Green line depicts the contour line of coupling $\equiv 0.5$. Orange patches indicate the location of the subsurface ridges beneath the Indo-Gangetic Plains. The Main Frontal Thrust fault is outlined in black.

wedge is small during the interseismic period. If a significant amount of permanent deformation were present, the long-term convergence rate predicted by the geodetic data would be higher than the convergence rate used to infer the pattern of coupling on the MHT. All together, these results 
demonstrate that the Himalayas is a highly three-dimensional mountain range. Yet, it has been described by several two-dimensional cross-sectional models (Bettinelli et al. , 2006; Bilham et al. , 1997; Lindsey et al. , 2018). The 2D approximation is likely a poor approximation as these models are inefficient to describe geodetic observations resulting from ongoing plate convergence and/or spatially variable tectonic heterogeneities.

To investigate lateral variations in collisional structure we also compare (i) the Arc-Parallel Topography Anomalies (Hetényi et al. , 2016b), which define the topography differences from the average arc-perpendicular profile, (ii) the 0.5 contour line of coupling, and (iii) the location of the three subsurface ridges (Fig 4b). The variation of the Arc-Parallel Topography Anomalies exceed $500 \mathrm{~m}$ with a number of alternating negative and positive patches throughout the arc. Remarkably, the higher values at the front of the range are located where the coupling is low and the three subsurface ridges come across the Main Frontal Thrust. The western boundary near $76.5^{\circ} \mathrm{E}$, aligned with the DelhiHaridwar ridge (DHR), is visible in the topography anomalies. The middle boundary near $82.5^{\circ} \mathrm{E}$, aligned with the Faizabad ridge (FR), as well as the eastern end of the Munger-Saharsa ridge (MSR) near $87.5^{\circ} \mathrm{E}$, are also visible in the topography anomalies. This latter is certainly a major boundary in (or of) the India plate (Hetényi et al. , 2016b). The correlation between the Arc-Parallel Topography Anomalies and coupling suggests that regions with strongly positive Arc-Parallel Topography Anomalies are likely more aseismic, as already observed in subduction zones (Song \& Simons, 2003).

To conclude, we propose that inherited structures along the Himalayan arc induce a zonation of interseismic coupling along the plate interface. Regardless of uncertainties, our first probabilistic estimate of interseismic coupling along the MHT suggests that the Himalayan megathrust is segmented by regions of low coupling. These low-coupled patches overlap with inherited structures. Despite competing hypotheses, the segmentation of the orogen into these blocks is also confirmed in the along-strike rupture extension of historical earthquakes. Large earthquakes of the past millennium do not propagate across the segment boundaries defined by lower plate inherited structure (Hetényi et al. , 2016b; Gahalaut \& Arora, 2012). Therefore, the here identified low-coupled patches potentially set three boundaries for the lateral extent of potential megathrust earthquakes. From a general agreement between previous results (Ader et al. , 2012; Stevens \& Avouac, 2015), geodetic data, and geological constraints, our results confirm that the fraction of anelastic deformation in the highly-coupled regions might be within uncertainties of the geodetic data $(\leq 10 \%)$.

These new findings also highlight important targets for future studies, which will be essential to question how these segment boundaries control interseismic strain accumulation. Further GPS campaigns should assist in answering this challenging but crucial question. By the same token, these new results are of practical importance to seismic hazard analysis where effort is spent attempting to place limits on the probable lateral extension of future earthquakes across the whole Himalayan region.

\section{Acknowledgements}

This study was funded by the SNSF 2-77090-14 project Swiss-AlpArray SINERGIA (L.D.Z.) and the E.R.C. Starting Grant GEO-4D (R.J.). Numerical simulations were performed on ENS cluster Euler, Paris. We thank J.-P. Avouac, G. Hetény, M. Simons, L. Bollinger, C. Pranger, A. Gualandi, 
K. Wang, and S. Michel for constructive comments and discussions. We are grateful to G. Hetény for providing us with GMT scripts to plot Fig. 1 and the Arc-Parallel Topography Anomalies (Hetényi et al. , 2016b).

\section{References}

Ader, Thomas, Avouac, Jean-Philippe, Liu-Zeng, Jing, Lyon-Caen, Hélène, Bollinger, Laurent, Galetzka, John, Genrich, Jeff, Thomas, Marion, Chanard, Kristel, Sapkota, Soma Nath, et al. . 2012. Convergence rate across the Nepal Himalaya and interseismic coupling on the Main Himalayan Thrust: Implications for seismic hazard. Journal of Geophysical Research: Solid Earth (19782012), 117(B4).

Arora, BR, Gahalaut, VK, \& Kumar, Naresh. 2012. Structural control on along-strike variation in the seismicity of the northwest Himalaya. Journal of Asian Earth Sciences, 57, 15-24.

Avouac, Jean-Philippe. 2015a. Mountain building: From earthquakes to geologic deformation. Treatise on Geophysics, , 6, 381-432.

Berthet, Théo, Ritz, Jean-François, Ferry, Matthieu, Pelgay, Phuntsho, Cattin, Rodolphe, Drukpa, Dowchu, Braucher, Régis, \& Hetényi, György. 2014. Active tectonics of the eastern Himalaya: New constraints from the first tectonic geomorphology study in southern Bhutan. Geology, 42(5), 427-430.

Bettinelli, Pierre, Avouac, Jean-Philippe, Flouzat, Mireille, Jouanne, François, Bollinger, Laurent, Willis, Pascal, \& Chitrakar, Gyani Raja. 2006. Plate motion of India and interseismic strain in the Nepal Himalaya from GPS and DORIS measurements. Journal of Geodesy, 80(8-11), 567-589.

Bilham, Roger. 2009. The seismic future of cities. Bulletin of Earthquake Engineering, 7(4), 839.

Bilham, Roger. 2015. Seismology: raising kathmandu. Nature Geoscience, 8(8), 582.

Bilham, Roger, \& England, Philip. 2001. Plateau 'pop-up'in the great 1897 Assam earthquake. Nature, 410(6830), 806.

Bilham, Roger, Larson, Kristine, Freymueller, Jeffrey, Jouanne, F, LeFort, P, Leturmy, P, Mugnier, JL, Gamond, JF, Glot, JP, Martinod, J, et al. . 1997. GPS measurements of present-day convergence across the Nepal Himalaya. Nature, 386(6620), 61-64.

Bilham, Roger, Mencin, David, Bendick, Rebecca, \& Bürgmann, Roland. 2017. Implications for elastic energy storage in the Himalaya from the Gorkha 2015 earthquake and other incomplete ruptures of the Main Himalayan Thrust. Quaternary International, 462, 3-21.

Bollinger, L, Avouac, JP, Cattin, R, \& Pandey, MR. 2004. Stress buildup in the Himalaya. Journal of Geophysical Research: Solid Earth (1978-2012), 109(B11). 
Bollinger, Laurent, Sapkota, Soma Nath, Tapponnier, Paul, Klinger, Yann, Rizza, Magali, Van Der Woerd, Jerome, Tiwari, DR, Pandey, R, Bitri, Adnand, \& Bes de Berc, S. 2014. Estimating the return times of great Himalayan earthquakes in eastern Nepal: Evidence from the Patu and Bardibas strands of the Main Frontal Thrust. Journal of Geophysical Research: Solid Earth, 119(9), 7123-7163.

Cattin, R, \& Avouac, JP. 2000. Modeling mountain building and the seismic cycle in the Himalaya of Nepal. Journal of Geophysical Research, 105(B6), 13389-13407.

Chen, Wang-Ping, \& Molnar, Peter. 1990. Source parameters of earthquakes and intraplate deformation beneath the Shillong Plateau and the northern Indoburman ranges. Journal of Geophysical Research: Solid Earth, 95(B8), 12527-12552.

Chlieh, Mohamed, Avouac, Jean-Philippe, Sieh, Kerry, Natawidjaja, Danny Hilman, \& Galetzka, John. 2008. Heterogeneous coupling of the Sumatran megathrust constrained by geodetic and paleogeodetic measurements. Journal of Geophysical Research: Solid Earth, 113(B5).

Ciesin, Ciat. 2005. Gridded population of the world version 3 (GPWV3): population density grids. Palisades, NY: Socioeconomic Data and Applications Center (SEDAC), Columbia University.

Dal Zilio, Luca, van Dinther, Ylona, Gerya, Taras, \& Avouac, Jean-Philippe. 2019. Bimodal seismicity in the Himalaya controlled by fault friction and geometry. Nature communications, 10(1), 48.

Duputel, Zacharie, Agram, Piyush S, Simons, Mark, Minson, Sarah E, \& Beck, James L. 2014. Accounting for prediction uncertainty when inferring subsurface fault slip. Geophysical Journal International, 197(1), 464-482.

Gahalaut, VK, \& Arora, BR. 2012. Segmentation of seismicity along the Himalayan Arc due to structural heterogeneities in the under-thrusting Indian plate and overriding Himalayan wedge. Episodes, 35(4), 493-500.

Gahalaut, VK, \& Kundu, Bhaskar. 2012. Possible influence of subducting ridges on the Himalayan arc and on the ruptures of great and major Himalayan earthquakes. Gondwana Research, 21(4), 1080-1088.

Grandin, Raphaël, Vallée, Martin, Satriano, Claudio, Lacassin, Robin, Klinger, Yann, Simoes, Martine, \& Bollinger, Laurent. 2015. Rupture process of the $M w=7.92015$ Gorkha earthquake (Nepal): insights into Himalayan megathrust segmentation. Geophysical Research Letters, 42(20), 8373-8382.

Gualandi, Adriano, Avouac, Jean-Philippe, Galetzka, John, Genrich, Joachim F, Blewitt, Geoffrey, Adhikari, Lok Bijaya, Koirala, Bharat Prasad, Gupta, Ratnamani, Upreti, Bishal Nath, Pratt-Sitaula, Beth, et al. . 2017. Pre-and post-seismic deformation related to the 2015, Mw 7.8 Gorkha earthquake, Nepal. Tectonophysics, 714, 90-106. 
Hetényi, György, Roux-Mallouf, Le, Berthet, Théo, Cattin, Rodolphe, Cauzzi, Carlo, Phuntsho, Karma, Grolimund, Remo, et al. . 2016a. Joint approach combining damage and paleoseismology observations constrains the 1714 AD Bhutan earthquake at magnitude $8 \pm 0.5$. Geophysical Research Letters, 43(20).

Hetényi, György, Cattin, Rodolphe, Berthet, Théo, Le Moigne, Nicolas, Chophel, Jamyang, Lechmann, Sarah, Hammer, Paul, Drukpa, Dowchu, Sapkota, Soma Nath, Gautier, Stéphanie, et al. . 2016b. Segmentation of the Himalayas as revealed by arc-parallel gravity anomalies. Scientific reports, 6, 33866 .

Hirn, Alfred, Lepine, Jean-Claude, Jobert, Georges, Sapin, Martine, Wittlinger, Gérard, Zhong Xin, Xu, En Yuan, Gao, Xiang Jing, Wang, Ji Wen, Teng, Shao Bai, Xiong, Pandey, M. R., \& Tater, J. M. 1984. Crustal structure and variability of the Himalayan border of Tibet. Nature, 307(01), 23 EP -.

Hough, Susan E, \& Roger, Bilham. 2008. Site response of the Ganges basin inferred from reevaluated macroseismic observations from the 1897 Shillong, 1905 Kangra, and 1934 Nepal earthquakes. Journal of Earth System Science, 117(2), 773-782.

Hubbard, Judith, Almeida, Rafael, Foster, Anna, Sapkota, Soma Nath, Bürgi, Paula, \& Tapponnier, Paul. 2016. Structural segmentation controlled the $2015 \mathrm{Mw} 7.8$ Gorkha earthquake rupture in Nepal. Geology, 44(8), 639-642.

Jackson, Michael, \& Bilham, Roger. 1994. Constraints on Himalayan deformation inferred from vertical velocity fields in Nepal and Tibet. Journal of Geophysical Research, 99, 13-897.

Jolivet, R, Simons, M, Agram, PS, Duputel, Z, \& Shen, Z-K. 2015. Aseismic slip and seismogenic coupling along the central San Andreas Fault. Geophysical Research Letters, 42(2), 297-306.

Kreemer, Corné, Blewitt, Geoffrey, \& Klein, Elliot C. 2014. A geodetic plate motion and Global Strain Rate Model. Geochemistry, Geophysics, Geosystems, 15(10), 3849-3889.

Kumar, Senthil, Wesnousky, Steven G, Jayangondaperumal, R, Nakata, T, Kumahara, Y, \& Singh, Vimal. 2010. Paleoseismological evidence of surface faulting along the northeastern Himalayan front, India: Timing, size, and spatial extent of great earthquakes. Journal of Geophysical Research: Solid Earth, 115(B12).

Lay, Thorne. 2015. The surge of great earthquakes from 2004 to 2014. Earth and Planetary Science Letters, 409, 133-146.

Le Roux-Mallouf, Romain, Ferry, Matthieu, Ritz, Jean-François, Berthet, Théo, Cattin, Rodolphe, \& Drukpa, Dowchu. 2016. Paleoseismic evidence for two major historical earthquakes in Bhutan: new insight for rupture segmentation along the Himalayan arc. Page 7105 of: EGU General Assembly Conference Abstracts, vol. 18. 
Lindsey, Eric O, Almeida, Rafael, Mallick, Rishav, Hubbard, Judith, Bradley, Kyle, Tsang, Louisa LH, Liu, Yixiang, Burgmann, Roland, \& Hill, Emma M. 2018. Structural Control on Down-dip Locking Extent of the Himalayan Megathrust. Journal of Geophysical Research: Solid Earth.

Loveless, John P, \& Meade, Brendan J. 2011. Spatial correlation of interseismic coupling and coseismic rupture extent of the $2011 \mathrm{Mw}=9.0$ Tohoku-oki earthquake. Geophysical Research Letters, 38(17).

Mahesh, P, Rai, SS, Sivaram, K, Paul, Ajay, Gupta, Sandeep, Sarma, Rajagopala, \& Gaur, VK. 2013. One-dimensional reference velocity model and precise locations of earthquake hypocenters in the Kumaon-Garhwal Himalaya. Bulletin of the Seismological Society of America, 103(1), 328-339.

Marechal, Anais, Mazzotti, Stephane, Cattin, Rodolphe, Cazes, Gael, Vernant, Philippe, Drukpa, Dowchu, Thinley, Kinzang, Tarayoun, Alizia, Roux-Mallouf, Le, Thapa, Bal Bahadur, et al. . 2016. Evidence of interseismic coupling variations along the Bhutan Himalayan arc from new GPS data. Geophysical Research Letters, 43(24).

Minson, SE, Simons, M, \& Beck, JL. 2013. Bayesian inversion for finite fault earthquake source models I-Theory and algorithm. Geophysical Journal International, 194(3), 1701-1726.

Monsalve, G, Sheehan, A, Schulte-Pelkum, V, Rajaure, S, Pandey, MR, \& Wu, F. 2006. Seismicity and one-dimensional velocity structure of the Himalayan collision zone: Earthquakes in the crust and upper mantle. Journal of Geophysical Research: Solid Earth, 111(B10).

Moreno, M, Melnick, Daniel, Rosenau, M, Bolte, John, Klotz, Jan, Echtler, H, Baez, J, Bataille, K, Chen, J, Bevis, M, et al. . 2011. Heterogeneous plate locking in the South-Central Chile subduction zone: Building up the next great earthquake. Earth and Planetary Science Letters, 305(3-4), 413-424.

Mugnier, Jean-Louis, Huyghe, Pascale, Leturmy, Pascale, \& Jouanne, Franois. 2004. Episodicity and rates of thrust-sheet motion in the Himalayas (western Nepal).

Mugnier, Jean-Louis, Jouanne, François, Bhattarai, Roshan, Cortes-Aranda, Joaquim, Gajurel, Ananta, Leturmy, Pascale, Robert, Xavier, Upreti, Bishal, \& Vassallo, Riccardo. 2017. Segmentation of the Himalayan megathrust around the Gorkha earthquake (25 April 2015) in Nepal. Journal of Asian Earth Sciences.

Pandey, MR, Tandukar, RP, Avouac, JP, Lave, J, \& Massot, JP. 1995. Interseismic strain accumulation on the Himalayan crustal ramp (Nepal). Geophysical Research Letters, 22(7), 751-754.

Rajendran, CP, \& Rajendran, Kusala. 2005. The status of central seismic gap: a perspective based on the spatial and temporal aspects of the large Himalayan earthquakes. Tectonophysics, 395(12), 19-39.

Ruh, Jonas B, Sallarès, Valentí, Ranero, César R, \& Gerya, Taras. 2016. Crustal deformation dynamics and stress evolution during seamount subduction: High-resolution 3-D numerical modeling. Journal of Geophysical Research: Solid Earth, 121(9), 6880-6902. 
Sapkota, SN, Bollinger, L, Klinger, Y, Tapponnier, P, Gaudemer, Y, \& Tiwari, D. 2013. Primary surface ruptures of the great Himalayan earthquakes in 1934 and 1255. Nature Geoscience, 6(1), 71-76.

Shaw, Bruce E, Milner, Kevin R, Field, Edward H, Richards-Dinger, Keith, Gilchrist, Jacquelyn J, Dieterich, James H, \& Jordan, Thomas H. 2018. A physics-based earthquake simulator replicates seismic hazard statistics across California. Science advances, 4(8), eaau0688.

Simons, Mark, Fialko, Yuri, \& Rivera, Luis. 2002. Coseismic deformation from the 1999 M w 7.1 Hector Mine, California, earthquake as inferred from InSAR and GPS observations. Bulletin of the Seismological Society of America, 92(4), 1390-1402.

Singer, Julia, Kissling, Edi, Diehl, Tobias, \& Hetényi, György. 2017. The underthrusting Indian crust and its role in collision dynamics of the Eastern Himalaya in Bhutan: Insights from receiver function imaging. Journal of Geophysical Research: Solid Earth, 122(2), 1152-1178.

Singh, Satish C, Hananto, Nugroho, Mukti, Maruf, Robinson, David P, Das, Shamita, Chauhan, Ajay, Carton, Helene, Gratacos, Bruno, Midnet, Stephan, Djajadihardja, Yusuf, et al. . 2011. Aseismic zone and earthquake segmentation associated with a deep subducted seamount in Sumatra. Nature Geoscience, 4(5), 308.

Song, Teh-Ru Alex, \& Simons, Mark. 2003. Large trench-parallel gravity variations predict seismogenic behavior in subduction zones. Science, 301(5633), 630-633.

Stevens, VL, \& Avouac, J-P. 2016. Millenary Mw>9.0 earthquakes required by geodetic strain in the Himalaya. Geophysical Research Letters, 43(3), 1118-1123.

Stevens, VL, \& Avouac, JP. 2015. Interseismic coupling on the main Himalayan thrust. Geophysical Research Letters, 42(14), 5828-5837.

Thakur, VC, Joshi, M, Sahoo, D, Suresh, N, Jayangondapermal, R, \& Singh, A. 2014. Partitioning of convergence in Northwest Sub-Himalaya: estimation of late Quaternary uplift and convergence rates across the Kangra reentrant, North India. International Journal of Earth Sciences, 103(4), 1037-1056.

Valdiya, KS. 1976. Himalayan transverse faults and folds and their parallelism with subsurface structures of north Indian plains. Tectonophysics, 32(3-4), 353-386.

Vernant, Philippe, Bilham, R, Szeliga, W, Drupka, D, Kalita, S, Bhattacharyya, AK, Gaur, VK, Pelgay, P, Cattin, Rodolphe, \& Berthet, Theo. 2014. Clockwise rotation of the Brahmaputra Valley relative to India: Tectonic convergence in the eastern Himalaya, Naga Hills, and Shillong Plateau. Journal of Geophysical Research: Solid Earth, 119(8), 6558-6571.

Wallace, K, Bilham, R, Blume, F, Gaur, VK, \& Gahalaut, V. 2005. Surface deformation in the region of the 1905 Kangra Mw= 7.8 earthquake in the period 1846-2001. Geophysical Research Letters, 32(15). 
Zheng, Gang, Wang, Hua, Wright, Tim J, Lou, Yidong, Zhang, Rui, Zhang, Weixing, Shi, Chuang, Huang, Jinfang, \& Wei, Na. 2017. Crustal Deformation in the India-Eurasia Collision Zone From 25 Years of GPS Measurements. Journal of Geophysical Research: Solid Earth, 122(11), 92909312.

Zhu, Lupei, \& Rivera, Luis A. 2002. A note on the dynamic and static displacements from a point source in multilayered media. Geophysical Journal International, 148(3), 619-627. 